\title{
O papel da batalha: a disputa pela vitória de Montijo na publicística do século XVII
}

\author{
Carlos Ziller Camenietzki \\ Universidade Federal do Rio de Janeiro \\ Rio de Janeiro, RJ, Brasil \\ ziller@historia.ufrj.br \\ Daniel Magalhães Porto Saraiva \\ Université de Paris IV \\ Paris, França \\ magalhaesporto@hotmail.com \\ Pedro Paulo de Figueiredo Silva \\ Universidade Federal do Rio de Janeiro \\ Rio de Janeiro, RJ, Brasil \\ pedropaulofsilva@yahoo.com.br
}

\section{RESUMO}

A batalha de Montijo, ocorrida no dia 26 de maio de 1644, foi a primeira grande batalha da Guerra da Restauração Portuguesa (1640-68) e foi vencida por ambos os combatentes. Os comandantes castelhanos declararam sua vitória logo após o término do enfrentamento; houve ainda a publicação de relaçôes, poemas e crônicas do acontecido. Os portugueses também se declararam vitoriosos no mesmo combate, publicando folhetos e apologias e inserindo sua narrativa dos acontecimentos em obras de história. O confronto entre textos de uns e de outros, bem como das circunstâncias de suas ediçóes, permite identificar o caráter político da disputa pela vitória em uma batalha já terminada. Com isso, identifica-se o esforço de vencer a batalha na opinião e na diplomacia do século XVII.

Palavras-chave: Restauração Portuguesa; batalha de Montijo; imprensa; relaçóes de guerra; opiniáo pública.

\begin{abstract}
The Battle of Montijo, occurred on May 26 ${ }^{\text {th }}$, 1644, was the first great battle of the Portuguese Restoration (1640-1668), and was conquered by both opponents. The Castilian commanders declared their victory soon after the end of combat; there was also the publishing of reports, poems, and chronicles about the event. The Portuguese also declared themselves as the winners of the same battle, publishing tracts and apologias and introducing their perspective on the battle's narrative into History works. The comparison between Portuguese and Castilian texts, as well as the circumstances of their publication, points to the political character of the dispute for victory in a finished battle. It also identifies the effort to win the battle in seventeenth-century public opinion and diplomacy.
\end{abstract}

Keywords: Portuguese Restoration; Montijo Battle; press; war relations; public opinion.

* Os autores agradecem à Capes e ao CNPq por ter fornecido os meios que possibilitaram este trabalho. Artigo recebido em 23 de março de 2012 e aceito em 14 de maio de 2012. 
No dia 26 de maio de 1644, nos campos de Montijo, na Estremadura castelhana, as forças invasoras portuguesas chefiadas por Mathias de Albuquerque enfrentaram as tropas locais de defesa, comandadas à distância pelo marquês de Torrecusa e no terreno pelo barão de Moligen. Trata-se do primeiro grande confronto em campo aberto da guerra que opôs a Monarquia Católica ao Portugal Restaurado e, ainda que os principais interesses militares de Madri estivessem do outro lado da Península, na Catalunha, seu resultado deveria importar bastante no desenvolvimento do conflito. Ao que tudo indica, assim foi.

É de se lembrar que o episódio ocorreu numa época marcada pelos derradeiros movimentos da Guerra dos Trinta Anos, quando as principais forças já haviam iniciado as conversaçóes que iriam terminar na celebração da Paz da Westfália poucos anos depois. No que toca especificamente à Península Ibérica, a guerra continuaria intensa por mais uma dúzia de anos entre castelhanos e franceses, mesmo após a tomada de Barcelona e a redução da revolta catalá, e por mais vinte anos entre portugueses e castelhanos.

O mais interessante no exame da batalha de Montijo, e o que a torna singular, é o fato de que ambas as partes em conflito proclamaram imediatamente a vitória; como se possível fosse haver dois vencedores do mesmo combate. Para essa inimaginável situação, nem mesmo Salomão, nem mesmo a intervenção divina direta poderia justificar o que ambos os contendores afirmavam, e o que os historiadores de Castela e os de Portugal repetiram insistentemente acerca do feito por longo tempo. É curioso constatar que até os nossos dias, já no século XXI, o problema da vitória nessa batalha ainda se apresente. Em 2005, a população da cidade de Montijo encenou uma representaçáo teatral, com mais de 250 moradores atuando, em que a vitória castelhana na batalha era o tema principal ${ }^{1}$. Com isso, fica aberta uma rica perspectiva no estudo dessa guerra e das principais modalidades de obtenção da vitória naquele tempo, o que impóe um conjunto de interrogaçôes acerca da "opinião pública" e do seu papel na definição das questôes políticas daqueles anos.

O conflito luso-castelhano do qual se trata iniciou-se em dezembro de 1640, poucos meses após a revolta da Catalunha, e alongou-se por 28 anos. Portugueses destronaram d. Felipe IV do reino de Portugal e ali colocaram d. João de Bragança, João IV, dando início a um tempo bastante conturbado no reino. Seguiram-se imediatamente esforços de consolidação do novo governo, tentativas de contragolpe e até mesmo de assassinato do Bragança; despachos acelerados aos domínios do ultramar; prisôes de nobres portugueses; fugas de fidalgos e de nobres de um lado ao outro da fronteira etc. De fato, os primeiros anos da Restauração foram tempos de grandes tensôes e de grandes conflitos em Portugal, sobretudo por envolver a gente nobre, que ademais demorou bastante a se alinhar majoritariamente ao novo governo. Se as populaçóes urbanas e a maior parte do clero - com grande dissensão na mais alta hierarquia - aderiram quase que imediatamente, a nobreza ficou dividida entre a antiga fidelidade a Felipe IV e a nova, e bastante real, possessão do reino pelo Bragança ${ }^{2}$. Não é exagerado afirmar que

\footnotetext{
${ }^{1}$ Cf. La Ventana de las Vegas Bajas, ago. 2005. p. 16. Disponível em: <http://www.ventanadigital.com/portal/lv/la_ ventana_sep05.pdf>.

${ }^{2}$ A bibliografia da Restauração é bastante extensa; começa ainda no tempo em que as armas estavam quentes e se alonga mesclada a problemas de épocas posteriores, que nada ou quase nada tinham a ver com a natureza daquele conflito. Nos últimos trinta anos, diversas análises mostram um renovado interesse pela época da Restauraçáo, por exemplo: TORGAL, Luís Reis. Ideologia politica e teoria de Estado na Restauração. Coimbra: Biblioteca Geral da Universidade, 1981. 2 v.; BEBIANO, Rui. A pena de Marte. Escrita da guerra em Portugal e na Europa (sécs. XVI-XVIII). Coimbra: Ediçóes Minerva, 2000; ESPÍRITO SANTO, Gabriel. A grande estratégia de Portugal na Restauração. Casal de Cambra: Caleidoscópio, 2009; FREITAS, Jorge Penim de. O combatente durante a Guerra da Restauração: vivência e comportamento dos militares a serviço da coroa portuguesa (1640 - 1668). Lisboa: Prefácio, 2007; CURTO, Diogo Ramada. Cultura política no tempo dos Felipes. Lisboa: Ediçôes 70, 2011; CUNHA, Mafalda Soares da; COSTA, Leonor Freire. D. João IV. Lisboa: Círculo de Leitores, 2006. Na Espanha e ainda em outros países da Europa, as possibilidades que o tema oferece foram aproveitadas por diversos estudiosos, por exemplo: SCHAUB, Jean-Frédéric. Le Portugal au temps du Compte-Duc D'Olivares: le conflit de juridictions comme exercice de la politique. Madrid: Casa de Velázquez, 2001; ALVAREZ, Fernando Bouza. Portugal
} 
cerca da metade da nobreza titulada — índice bastante bom para perceber o alinhamento da fidalguia - permaneceu fiel ao Habsburgo e desempenhou um papel importante nas açóes da Monarquia ${ }^{3}$.

Neste quadro, e já iniciados os feitos de guerra em meados de 1641, para Portugal, invadir terras de Castela não representava uma tentativa de tomar efetivamente domínios da Monarquia e submetê-los ao Bragança, com esperanças de conquistas territoriais duradouras, mas registrar com o sangue inimigo que os lusitanos também mantinham poder de fogo ofensivo. Por outro lado, a vitória em Montijo servia para confirmar a capacidade bélica da nobreza fiel ao Bragança, apaziguando assim as tensóes de um reino assolado por incertezas e ameaças conspiratórias ${ }^{4}$. Vencê-la era decisivo naqueles primeiros anos da guerra.

Para Castela, derrotar uma primeira grande incursão lusitana era forma de fortalecer a tese da insuficiência portuguesa, da fraqueza dos Bragança e de sua destemperada rebeldia. Embora a Monarquia Católica estivesse num período de certa debilidade bélica, com o arrastar-se do problema cataláo, a irresolução do conflito em Flandres e a entrada da França na Península via Barcelona não seria facilmente absorvível uma primeira grande derrota na Estremadura castelhana diante dos exércitos do duque rebelde.

Até então, mas também depois disso, os enfrentamentos nas fronteiras envolviam algumas dezenas, ou mesmo centenas, de homens em operaçôes de pilhagem sobre aldeias e populaçôes que mal podiam se defender, ou em cercos breves de cidades bem protegidas ${ }^{5}$. Nos campos de Montijo, o enfrentamento envolveu milhares de soldados de cada lado, com mais de mil cavaleiros cada, armamento pesado e tralha de guerra volumosa - carros, alimentos, munição etc. Não é estimativa ruim tomar o número de envolvidos na casa de 15 mil pessoas, contando os combatentes de ambos os lados e o pessoal de apoio. Para o século XVII, e para tempos posteriores também, isso já é um número bastante elevado.

No entanto, a vitória não foi resolvida com esses homens. A batalha de Montijo poderia confirmar a ideia de que qualquer combate se decide em duas dimensôes: uma material, em que os homens se enfrentam de fato; e outra simbólica, da narrativa do enfrentamento. Porém, nem assim, na sequência dos acontecimentos, se conseguiu consenso sobre o resultado desse embate. Ambas as partes venceram! Ou seja, material ou simbolicamente ninguém venceu. Com o passar das décadas, com a resolução da independência política portuguesa, o contraste acabou por se transformar em literatura, em matéria de historiadores, sem contudo encontrar solução definitiva até nossos dias, até o tempo de agora! E, certamente, este texto não é uma tentativa de atribuir a vitória a uma das partes.

Quando derrubaram o governo de seu rei castelhano, os portugueses se viram diante da emergência de recomposiçáo dos grupos dirigentes da sociedade em vista das necessidades imperiosas da formação de um novo governo e do enfrentamento certo com a principal força militar da Europa daqueles anos. Como a nobreza permaneceu dividida por algum tempo, a política acabou se lançando às ruas e às

no tempo dos Felipes. Política, cultura, representaçóes. Lisboa: Cosmos, 2000; VALLADARES, Rafael. La rebelion de Portugal (guerra, conflicto y poderes en monarquia hispanica). Valladolid: Junta Castilla-Leon, 1998. Obras dos tempos anteriores serão referidas ao longo deste trabalho.

${ }^{3}$ Cf. ALVAREZ, Fernando Bouza. Portugal no tempo dos Felipes, op. cit. p. 271-291.

${ }^{4}$ MENESES, Luís de, conde da Ericeira. História de Portugal Restaurado. Porto: Livraria Civilização, 1945. v. I, p. 148. Esta obra foi publicada pela primeira vez ainda em 1679.

5 "Esta foi a primeira batalha, que nesta guerra se deu de poder a poder, e por tal podem os que observam cousas tomar dela indicação ajuizando pelo sucesso dos que pode haver futuros; porque bem mostraram aqui os portugueses, que nem rotos, e desbaratados se podem ter por vencidos, porque em quanto conservam com a vida o valor, nenhuma dificuldade lho pode atropelar". Relaçam dos gloriosos svcessos que as armas de Sua Magestade ElRey D. João IV N. S. tiveram nas terras de Castella, neste anno de 1644 até a memorável Victoria de Montijo. Lisboa: Antonio Alvarez, 1644. p. 22. 
praças, com manifestaçóes típicas do tempo e dentro dos limites que as comportavam: luminárias, procissôes etc. A característica que mais importa aqui é a surpreendente maré de publicaçôes que acompanhou a abertura do debate político nos primeiros anos da Restauração. Publicava-se intensamente sobre os acontecimentos: livros, tratados, folhetos, cartazes, poemas, até mesmo o primeiro periódico lusitano saiu em novembro de 1641. Portugal publicava, e precisava muito disso para consolidar internamente a nova configuração do poder. Esses textos eram o veículo pelo qual as notícias dos acontecimentos chegavam às pessoas, ao público, conformando já alguma participação política das populaçóes urbanas do reino. Eram também os meios pelos quais os autores divulgavam suas ideias e apresentavam suas propostas para a política.

Até Montijo, centenas e centenas de impressos já haviam circulado em Lisboa narrando ou discutindo acontecimentos bélicos e políticos ligados à Restauração. Porém, essa batalha acabou gerando mais papéis do que qualquer outra nessa guerra. Problema certamente vinculado à ausência total de consenso mínimo quanto ao vencedor do confronto, quanto ao número de homens envolvidos no combate, à quantidade de peças de artilharia, aos cavaleiros etc.

Em Lisboa, ao que foi possível averiguar, foram publicados sete textos relativos à batalha, ainda que seja imaginável encontrar outras publicaçóes específicas e notícias manuscritas nas diversas bibliotecas e arquivos. Desse total, dois foram escritos em latim. Em português, há uma relação que cobre apenas o início da expedição de Mathias de Albuquerque até a tomada da cidade de Montijo, outra relação do conjunto dos feitos portugueses, incluindo a batalha, e, finalmente, uma apologia da vitória em resposta às publicaçôes do inimigo, que também evocavam para si a vitória na mesma batalha.

Os impressos favoráveis aos castelhanos também saíram publicados rapidamente em Sevilha, Salamanca e Madri e, logo após, se espalharam por várias cidades da Europa. Seus traços podem ser verificados em folhas volantes e em periódicos da época, ainda encontráveis diretamente nas bibliotecas do continente. De fato, o assunto não era algo que se limitava às fronteiras luso-castelhanas. $\mathrm{O}$ que estava em jogo era uma parte importante daquilo que já se caracterizou de "supremacia espanhola" no Velho Mundo, ou no mundo todo, caso se prefira ${ }^{6}$.

Talvez, o único acordo quanto ao enfrentamento seja a data e o local do combate: 26 de maio de 1644 nos campos da cidade de Montijo, das 9 horas da manhã até as 3 horas da tarde. Contam também as relaçóes que uma tropa portuguesa entrou pela Estremadura saqueando pequenas vilas e aldeias até que tomou a cidade de Montijo e, na sua retirada do local, foi abordada pelo exército de Castela.

A Relaçam dos gloriosos svcessos, publicada apenas em 15 de junho em Lisboa contando 32 páginas, assegura que as tropas portuguesas somavam 6 mil infantes, 1.100 cavalos e seis peças de artilharia. Esse contingente teria enfrentado 2.600 cavalos, muitos de couraça, e 7 mil infantes ${ }^{7}$. Destacar a superioridade da cavalaria inimiga é importante, pois as tropas montadas geralmente indicavam o poder ofensivo. Nos escritos castelhanos, porém, esses números são diversos. A Relación Verdadera de lo que Sucedió en veinte y seis de mayo pasado, que soma treze páginas, indica cifras bastante diferentes. Os portugueses seriam de 6 a 7 mil infantes, 1.400 cavalos, duzentos dragóes, seis peças de artilharia e ainda mais material bélico: "un trabuco para bombas, y mil gastadores con sus armas diferentes, con gran cantidad de municiones, petrechos de guerra y bastimentos, que conducia consigo para todo su ejército para tres semanas". As tropas castelhanas, por sua vez, reuniam gentes de diferentes lugares, convocadas

${ }^{6}$ Cf. ELLIOT, John H. et al. (Ed.). 1640: la Monarquía Hispánica en crisis. Barcelona: Crítica, 1992.

${ }^{7}$ Relaçam dos gloriosos svcessos, que as armas de Sua Magestade ElRey D. IOAM IV. N.S. tiueräo nas terras de Castela, neste anno de 1644 atè a memorauel victoria de Montijo. Lisboa: Antonio Alvarez, 1644. p. 12-14.

${ }^{8}$ Relación Verdadera de lo que Sucedió en veinte y seis de mayo pasado, en el Reencuentro que tuvieron las Armas De S. M. Con Las Del Rebelde Portugués en la Campana del Montijo. In: CALDERON, Serafín Estébanes, d. De la conquista y pérdida de Portugal. Madri: Impresso por A. Péres Dubrull, 1853. tomo I, p. 305. Collección de Escritores Castellanos - Historiadores. 
emergencialmente para fazer resistência a tão grande exército. Essas estariam na ordem aproximada de 4 mil infantes, 1.700 cavalos e duas peças de artilharia, somente?

É usual que as relaçôes apresentem as tropas inimigas como superiores tanto em número de homens como no aparelhamento militar, de forma a reforçar a bravura e o heroísmo de seus próprios exércitos. Afinal, a excitação do valor heroico é uma maneira de qualificar o esforço de guerra elidindo as condiçóes de combate dos próprios soldados, do exército como um todo e do reino. Do lado português, as dificuldades em estabelecer a nova monarquia, e o próprio governo, incidiam diretamente sobre sua capacidade de montar e manter um exército em condiçôes de enfrentar a máquina de guerra inimiga. Já o castelhano se via diante de muitas frentes de batalha, particularmente duas na Península Ibérica, o que impedia uma ação mais eficaz e concentrada contra seus inimigos lusitanos ${ }^{10}$.

As relaçóes de guerra, em geral, eram textos breves e muito informativos, editados rapidamente. Elas são pequenas: a maioria com oito ou doze páginas, e custavam pouco ${ }^{11}$. Contudo, trazem consigo uma grande quantidade de informaçóes sobre os acontecimentos; são permeadas de passagens catárticas em que os autores apelam para sentimentos religiosos, patrióticos, tornando a leitura ainda mais ágil, entretida e veloz. A essas características soma-se o frequente apelo à verdade, com testemunhos importantes alegados em favor do que se diz. Acrescente-se, ainda, o elogio de um ou outro chefe militar que comandou a ação descrita. O pequeno tamanho do relato é algo a não ser desprezado: tratava-se de um informativo ligeiro, deveria ser vendido e lido rapidamente; sua validade era muito curta, talvez táo curta quanto o próprio texto. Sempre é importante lembrar que não é comum a relação apresentar a autoria do texto. De fato, a autoria que importa para estes informativos é a autoria do feito e náo aquela da narrativa.

No que toca à batalha de Montijo, alguns escritos castelhanos atendem perfeitamente a essas características; é o caso da Relacion de la vitoria que tuuieron las armas, del Rey nuestro señor contra el tyrano de Portugal, ajustada de las personas, que han venido de Estremadura, y de las cartas que ha auido de aquella Prouincia ${ }^{2}$. Essa publicação agrega informaçóes de cartas e de testemunhos, mas soma apenas três páginas de texto sobre os acontecimentos do campo de batalha. As tropas portuguesas seriam de 8 mil infantes, mais de 1.500 cavalos com muita artilharia e suprimentos de muniçáo e alimentos, enquanto as de Castela seriam de 3 mil infantes e 1.500 cavalos.

Logo que inicia seu relato, o texto apresenta uma inusitada situação militar: o filho do conde de Montijo, don Antonio Portocarrero y Luna, teria matado com suas próprias mãos 62 soldados portugueses ${ }^{13}$. Isso significa que em um combate corporal em que a espada era a arma de base, esse bravo castelhano teria matado mais de dois portugueses a cada quinze minutos! O filho do conde de Montijo teria pelejado de forma tal que até mesmo os heróis das narrativas clássicas teriam ficado espantados. Montijo fora destruída pelos lusitanos e seria esperável que o filho do conde vingasse a perda com todo valor que se esperava dele, ainda que se propusesse uma verdadeira carnificina operada apenas por um homem.

Esta mesma relação qualifica a batalha da seguinte forma: "fue mas sangrienta que se ha visto en esta era" ${ }^{\prime 4}$. Ora, a mais sangrenta batalha de uma era é um evento notoriamente grande, para não dizer enorme, contudo três páginas foram capazes de resumi-lo numa linguagem simples e objetiva. Entre os acontecimentos narrados, os que fazem alusão a efeitos sobrenaturais, ou ao menos sugerem que Deus é

\footnotetext{
${ }^{9}$ Ibidem, p. 307.

${ }^{10}$ Nessa época, Castela tinha problemas político-militares com a Catalunha, os Países Baixos (Holanda), Portugal, França, Inglaterra, além de países do norte europeu e reinos alemães, em razão do seu envolvimento na Guerra dos Trinta Anos.

${ }^{11}$ Há relaçóes de guerra publicadas em Portugal nos primeiros dois anos do conflito que saíram apenas uma semana após o acontecimento descrito. Seu preço médio pode ser verificado pela taxação que aparece logo após as licenças de publicação.

${ }^{12}$ Impressa em Salamanca por Antonia Ramirez, 1644.

${ }^{13}$ Ibidem, p. 1.

${ }^{14}$ Ibidem, p. 3.
} 
um agente efetivo, quase sempre se apresentam e a narrativa explora o impacto destas informaçóes em favor do que está efetivamente contando ${ }^{15}$. Na relação que é foco desta análise, uma chuva intensa abre o argumento da colaboração da Providência com os intentos castelhanos:

aquel dia del Iueues, en qual, llouio tanto, que ni los nuestros, ni los portugueses, pudieron vsar de mas que dos, ò tres cargas los que mas, por estar mojada la poluora, y cuerda. Y en dizen que estuno nuestra dicha, porque si se pudiera vsar de las armas de fuego lleuariamos a la peor parte, como inferioes en numero y puesto, porque ellos peleauan desde las trincheras, y los nuestros a cuerpo descubierto, pero como inferiores en valor con la ocasion de mostrarle espada a espada y pica a pica, llevaró la peor parte ${ }^{16}$.

Segundo o relato, a chuva seria um castigo em razão da ofensa portuguesa ao provocar uma batalha em dia de festividades sacras, Corpus Christi.

De maneira geral, estes impressos ligeiros centram suas atençóes no número de soldados envolvidos e nos virtuosos, ou desvirtuados, valores que seria necessário apontar. Assim, a caracterização do sujeito envolvido no combate é de grande utilidade na construção de uma analogia entre um determinado exército e seu reino (bem como a descaracterização do alheio). No caso do último trecho, a participação de Deus é sugerida e nisso reside grande parte de sua eficácia.

Em textos como esse, o apelo racional é mínimo se comparado ao passional. Mesmo no caso de uma batalha ocorrida após três anos do início de uma guerra que parecia náo acontecer, as razóes de tal conflito não são apresentadas. Contudo, apresentam-se o inimigo e o combate de forma bastante restrita, como se todo o demais fosse informação da qual o leitor já dispusesse. Assim, as notícias são narradas a partir de uma breve apresentação dos contingentes e dos movimentos principais, ficando os momentos catárticos centrados na fúria e no desejo da matança, da vingança humana ou do castigo divino.

A caracterização feita das pessoas, militares ou não, envolvidas nesta batalha segue um padrão que pode ser observado em diversos outros relatos de guerra. A coincidência dos elementos expositivos, antes de ser casual, evidencia os nexos de composição dessas relaçóes: tratava-se de formar opiniáo entre os leitores quanto ao andamento do conflito. Com isso, as relaçóes de guerra adotam em sua grande maioria uma espécie de brevíssima "prosa epopeica"17.

Ao que se pode constatar no conjunto das relaçóes de guerra de 1644 e num memorial enviado a d. João IV pelo chefe militar português, as forças lusitanas intentavam atacar Albuquerque, vila de tamanho considerável, a fim de responder e estancar as constantes incursóes de Castela na raia portuguesa ${ }^{18}$. Ouguela, por exemplo, foi atacada no início de abril e a resistência dos moradores e dos soldados foi narrada em uma relação não menos curta e nem menos heroica, publicada em Lisboa ${ }^{19}$. Porém, ao final

\footnotetext{
${ }^{15}$ As relaçóes portuguesas desta mesma época costumam apresentar passagens em que as proezas dos soldados lusitanos parecem, ou são, milagrosas. Por exemplo, a passagem em que se conta o pouco efeito que os pelouros castelhanos faziam nos portugueses: "se isto não he milagre, he couza digna de admiração, \& consolação pera os portugueses, \& que lhe deve dar confiança, de que Deos os ampara" na Relaçam do Encontro que o mestre de campo Dom Nuno Mascarenhas teve com o inimigo em Montalvão. Lisboa: Manoel da Sylva, 1641. p. A2r.

${ }^{16}$ Ibidem, p. 2-3. O registro da incidência de forte chuva no combate também pode ser verificado em outro escrito castelhano: PARDO DE GAYOSO, Antonio. Octavas Heroicas. Sevilha: Juan Gomez de Blas, 1644. f. 8.

${ }^{17}$ Cf. CARVAlHO, Maria do Socorro Fernandes de. Poesia de agudeza em Portugal. Estudo retórico da poesia lírica e satírica escrita em Portugal no século XVII. São Paulo: Humanitas Editorial; Edusp; Fapesp, 2007.

${ }^{18}$ PIMENTA, Belisário. O memorial de Mathias de Albuquerque. Boletim da Biblioteca, Coimbra, v. XVI, 1944.

${ }^{19}$ Cf. Relaçam da Famosa Resistencia e Sinalada Vitoria, Qve os Portugueses alcançarão dos Castelhanos em Ouguela este Anno de 1644 a 9 de Abril, governando esta praça o Capitaó Pascoal da Costa. Lisboa: Impresso por Paulo Craesbeck, 1644. Nessa
} 
daquele mês, ao chegar aos muros de Albuquerque, o governador das armas portuguesas considerou que a investida seria fracassada, dado o seu sólido aparato de defesa. Com a intenção de provocar a primeira batalha de grandes proporçóes naquela guerra, o governador das armas passou a arrasar diversos povoados da região: primeiro, Villar del Rey, depois, a Villa Roca de la Sierra, Puebla, Montijo e, ao sair desta última, encontrou as tropas castelhanas. Eles esperavam a saída dos portugueses, cercando seu caminho de volta para Campo Maior - praça portuguesa de onde partiram.

Para além da divergência quanto ao número de soldados envolvidos, as relaçóes castelhanas e as portuguesas também destoam quanto ao desenrolar e quanto ao fim do combate. Com os terços formados, os castelhanos investiram com sua cavalaria; as forças de Portugal, também prontas para a refrega, resistiram num primeiro momento, mas acabaram por ceder pelo braço esquerdo. É interessante notar o cuidado adotado pelos lusitanos para descrever suas perdas. Unânime, entre as versóes portuguesas levantadas até agora, que os primeiros avanços castelhanos se deram exatamente pelo flanco comandado por tropas montadas de holandeses. Eles teriam recuado por medo da investida inimiga:

A [tropa] holandesa amedrontada com o grande número da Castelhana voltou logo a fugir, e o fez com tanto desacordo, que virando sobre o esquadráo de Ayres de Saldanha, que ia de vanguarda, o deixou roto, e aproveitando-se o inimigo desta desordem, vendo aberto aquele esquadrão, o investiu com toda a sua cavalaria pelo acabar de romper; mas, ainda que a nossa, que estava no corno direito, não socorreu, não pode acabar de o conseguir pela resistência, que lhe fez a infantaria, pelejando com muito perigo, pela fronte, e lado, que já tinha descoberto ${ }^{20}$.

A principal responsabilidade sobre a quebra da formação portuguesa, que teria levado à perda da artilharia, recai sobre as tropas de Holanda, empenhada também nesta guerra contra a Monarquia Católica. A desorganização dos bravos lusitanos seria, então, o resultado do medo sentido por seus aliados, e não algo próprio daqueles que defendiam sua independência política. A covardia holandesa teria desarrumado o esquadrão português de Ayres de Saldanha, morto em combate, e prejudicado a ação das tropas lusas. A insuficiência das tropas de Mathias de Albuquerque no início da batalha, responsável pela ilusão momentânea da derrota, é então atribuída aos holandeses.

Contudo, em um momento de breve concordância entre as relaçôes de Castela e as portuguesas, é possível identificar uma reação das tropas de Mathias de Albuquerque. Porém, as versôes divergem quanto ao grau de sucesso dessa nova investida. Diz a versão "verdadera" de Castela:

se deshicieron todos los escuadrones enemigos, no quedando de ellos sino un pequeño cuerpo apiñado, el cual se retiró un poco atrás, y nuestros soldados, no mirando á deshacer aquellos pocos que quedaban, aunque lo procuraron los cabos, sino se dieron al pillaje y desbalijo, no tratando de otra cosa sino de ésto y de salvar la presa, y ponerla en seguridad, cortando las cuerdas de las muías de tiro de artillería del enemigo y llevándoselas, se retiraron á Lobón y Talavera y por todos aquellos lugares, mucha gente nuestra, asi de caballería como de infantería, unos retirando los heridos, otros retirando la presa y otros llevando prisioneros, con que se nos deshicieron de todo punto los escuadrones y nuestra artillería y carros de municiones, y viéndolos mezclados con los enemigos, se retiraron á Lobón, dando

relaçáo podem ser vistos diversos dos argumentos heroicos aqui debatidos. Entre eles destaca-se a descrição da batalha que, além de contar com a ajuda "heroica" da população, se distingue pela oposição de forças: quarenta soldados da companhia do capitão Pascoal da Costa, vinte cavalos holandeses e setenta moradores (inclusive mulheres) que defendiam juntos um pequeno castelo contra mil cavalos de Castela. É interessante ressaltar que o documento indica ser a vila povoada por pouco mais de oitenta "vizinhos", o que realça o comprometimento dos setenta portugueses que se arriscaram na defesa, quase um português por casa. Também é possível observar o caso de um português que, mantendo-se fiel a Castela, atacou com posto de oficial o reino de Portugal.

${ }^{20}$ Relaçam dos gloriosos svcessos, op. cit. p. 15. 
por excusa que los cortaba el enemigo con su caballería; aunque se tornó á enviar por la artillería, no fué posible el volver, y la poca gente que quedó no fué posible en mucho rato tornarla á rehacer y formar escuadrones, por diligencias ordinarias v extraordinarias que se hicieron, y gran trabajo del General de la artillería, Maestre de campo Monroy, Pinatelo y Xedler, con lo cual se dio tiempo al enemigo á rehacerse cuanto pudo y sin que nadie se lo estorbase; $y$ si le quedara valor entonces para acometernos, juzgo que nos deshiciera, por hallarnos desordenados, y á cabo de este trabajo se hizo frente al enemigo y se rehizo nuestra gente. Y marchamos la vuelta de donde estaba, y fué tan poca, asi de la caballería que pudo recoger el barón de Molingen y el Teniente General, como de la infantería, que no fué bastante para acometerle al enemigo y acabarle de deshacer, el cual, cobrando su artillería y disparándonos algunos cañonazos á nuestros escuadrones, tomó su marcha bien cerrada, encaminándose á la vuelta del bosque del camino de Rotoba, siguiéndole algunas pequeñas tropas de nuestra caballería que habian quedado y nuestra infantería en escuadrones á su vista, le fuimos costeando hasta que se fué alargando mucho; con que después nos fuimos retirando al puesto de donde habiamos salido aquella mañana ${ }^{21}$.

Assim, a cobiça dos soldados de Castela ao pilhar o campo abandonado pelos portugueses teria permitido uma reorganização das tropas já derrotadas. $\mathrm{O}$ contra-ataque lusitano ter-se-ia limitado à retomada das peças de artilharia. Em seguida, eles teriam bombardeado os desorganizados castelhanos e partido em fuga acelerada, perseguidos por tropas da cavalaria do barão de Molingen.

$\mathrm{Na}$ relação portuguesa que foi tomada como modelo de comparação, os acontecimentos da batalha são tratados de modo bastante diferente. Afinal, o embate foi descrito por inimigos que se enfrentavam materialmente e seria estranho encontrar a mesma descrição em ambos os relatos.

Estava a nossa gente tão cortada pela do inimigo, que quando começou a melhorar-se, nem se podia servir dos piques, nem dos mosquetes, e arcabuzes; circunstâncias que todas mostram com evidência, quanto o valor excelente pode em muitos casos ser superior a toda a má fortuna. Assim o mostrou Mathias de Albuquerque, e os que nisto o acompanharam, porque sem embargo de se verem reduzidos a estado, que quaisquer outros ânimos, ainda que fossem valorosos, se descompuseram, e procuraram só algum meio para salvar as vidas, o não fizeram, antes aconselhando-se com o General da artilharia, e com os Mestres de Campo Luis da Sylua Telles, João de Saldanha, Francisco de Mello, e Martim Ferreira, resolveram todos pelejar à espada, não havendo já então dez soldados compostos, e unidos, e com esta resolução investiram ao inimigo à espada, pelejando divididos como estavam, com tâo deliberado valor, que lhe tornaram a ganhar a artilharia, e bagagens, e lhe mataram tanta gente, que o obrigaram a largar o campo, e ir se retirando descomposto contra Guadiana, que dista mais de uma légua do lugar da batalha, deixando toda esta campanha coberta de corpos mortos e armas, porque como a cólera dos nossos, com o aperto do perigo, se refinou, rompeu com fúria inexorável, e nenhum prisioneiro tomaram, pelejando tấo encarniçadamente, que a ninguém concediam vida. Quando o inimigo chegou ao Rio ia já desacordadamente fugindo, porque só nove tropas da sua cavalaria, e três esquadróes de infantaria dos nove com que entrou na batalha, se poderão ali formar para o passarem unidos, e muita gente se lhe afogou com a pressa; que se davam em passar da outra banda para se salvar22.

Alguns poucos e motivados portugueses foram capazes de reverter um dramático revés militar, amparados apenas em sua determinação. Ao contrário do relatado por Castela, não só eles recuperaram todos os seus canhóes, como puseram em fuga acelerada as tropas fiéis a seu antigo rei. O desacordo

${ }^{21}$ CALDERON, Serafín Estébanes, d. De la conquista y pérdida de Portugal, op. cit. p. 311-312. Outro impresso, contudo, destaca que sequer isso ocorrera: "Tomararóse al enemigo quinhetos cauallo para poder seruir, tres piezas de artilleria, otros dizen seis. Ciento y cinquenta carros con el tren de la artilleria, y bagaje riquisimo". Relacion de la vitoria qve tuuieron las armas, del Rey nuestro Señor contra el tyrano de Portugal, ajustada de las personas, que han venido de Estremadura, y de las cartas que ha auido de aquella Prouincia. Salamanca: Antonia Ramirez, 1644. p. 3.

${ }^{22}$ Relaçam dos Gloriosos Sucessos, op. cit. p. 17-18. 
quanto ao término da batalha não poderia ser maior: para as relações de Castela, os portugueses fogem perseguidos pelos castelhanos; para as relaçóes de Portugal, os castelhanos deixam o campo perseguidos pelos portugueses.

Em qualquer batalha daquele tempo, e de outros, sempre foram feitos prisioneiros. Em princípio, o vencedor aprisionava soldados derrotados ou vencidos e os trocava por soldados seus ou por dinheiro vivo, bens móveis etc. Assim, o registro dos soldados nesta batalha alcança uma dimensáo bastante importante quando se leva em consideração o fato de os castelhanos, ao menos em suas relaçôes da batalha, apresentarem um elenco de prisioneiros portugueses. Afinal, prender combatentes é coisa própria de vencedores.

Logo após a batalha, sai publicada em Sevilha uma carta que o marquês de Torrecusa teria enviado a d. Felipe IV, no próprio dia 26 de maio, mesmo não tendo sido testemunha dos acontecimentos, em que ele afirma terem feito muitos prisioneiros portugueses: "los prisioneros es grande cantidad, y entre otros, son el hijo del General de la Cavalleria, el Conde de Fiesco, um Coronel Aleman, um Teniente de Maesse de campo general" 23 . Outros impressos já citados fornecem lista mais detalhada.

Os lusitanos reconheceram a prisão de diversos dos seus no embate de Montijo já desde a Relaçam dos gloriosos svcessos. O problema é exposto de modo a certificar o leitor da normalidade de uma situaçáo que deveria ser invertida; afinal, quem vence aprisiona, não é aprisionado. $\mathrm{O}$ autor do texto expóe esse problema do seguinte modo:

E dos soldados se averiguou pelas listas depois do exército recolhido, que faltavam novecentos, mas entram neste número muitos dos bisonhos do terço novo que fugiram, que seriam mais de trezentos, e pouco menos de outros tantos, que o inimigo levou presos, e com estes forma o Conde Fiesco francês, o Mestre de Campo Eustachio Pique, Dom Diogo de Menezes e Fernão Pereira, Capitães de cavalos, Manoel de Saldanha, Jorge de Mello filho do General da cavalaria, e Dom Francisco de Almada Capitáes de infantaria, e outros três, ou quatro capitães, que foram presos depois de muito feridos, pelejando na primeira refrega ${ }^{24}$.

A Apologia de Luís Marinho de Azevedo, escrita em setembro, trata da prisão em termos bastante diferentes. Seu texto era obra de controvérsia contra escritos de Castela e náo faria sentido expor essa matéria sem detalhar o que teria movido os "bravos portugueses" a caírem aprisionados pelos inimigos:

Lo cierto es que en la [batalla] de Montijo nos llevaron ducientos prisioneros la mayor parte bisioños, que viendose muchos dellos heridos, y la confusion de nuestro exercito, entendiendo que estava de todo perdido, dejando la batalla, encaminaron a Lobon, y Talavera pensando que eran lugares nuestros, y esta fue la causa de aver tantos prisioneros $^{25}$.

Azevedo reconhece bem o problema e busca justificar e resolver a contradição com exemplos históricos: "no es esta la ves primera, que a un exercito vencedor, le tomo el contrario prisioneros con su cavalleria" 2.

\footnotetext{
${ }^{23}$ Copia de Carta que el excellentissimo señor Marques de Torrecusa embio a su Magestad. Sevilha: Juan Gomez de Blas, 1644.

${ }^{24}$ Relaçam dos gloriosos Svcessos, op. cit. p. 19-20.

${ }^{25}$ AZEVEDO, Luiz Marinho de. Apologia militar en defensa de la victoria de Montijo contra las relaciones de Castilla, y gazeta de Genoba, que la calumniaron mordaces, y la usurpan maliciosas. Lisboa: Lourenço de Anveres, 1644. p. 20.

${ }^{26}$ Ibidem.
} 
$\mathrm{Na}$ verdade, a ação dos combatentes remete diretamente o leitor à sua condição pátria, de maneira a convencê-lo de que aqueles que estavam no campo de batalha se identificavam com o próprio reino e seu povo. Assim, a emulação do valor patriótico não se limita ao soldado, mas é feita de forma a confirmar a superioridade de uma população inteira que passa a ser apresentada como de táo nobre valor quanto seus governantes o são de título. A origem social passa a importar menos, pois o que se objetiva é a formação de uma opiniáo pública que facilite a consolidação do projeto político do Bragança e auxilie na sua defesa. Essas características são observadas em relatos sobre diversas batalhas, como em uma relação sobre os eventos de abril e maio de 1644:

Está no termo de Vila de Serpa uma aldeia de poucos vizinhos chamada a Aldeia Nova fortificada com suas trincheiras, e guarnecida com uma companhia de gente paga. Saíram os inimigos de Paymogo, Alcaçaria, Serra, e Arouche com três tropas de cavalos, e trezentos infantes para roubarem algum gado, que os desta aldeia tinham, e assim levaram todos os que acharam à vista do lugar: desmandou-se um dos castelhanos de cavalo, e o alcaide da aldeia lhe atirou uma pedrada, de que o derrubou desacordado, e correndo a ele o matou com uma faca, e subindo no seu cavalo foi dar aviso ao alcaide-mor de Serpa, o qual acudiu com grande pressa ao socorro, mas já a tempo que o inimigo se tinha recolhido com o gado. Os moradores da aldeia quando viram que os inimigos lhe levavam seu remédio, imaginando que era menos o poder contrário, foram em alcance dos castelhanos como leóes furiosos, e sendo vinte e cinco somente se empenharam com eles de sorte que para salvarem as vidas lhes foi forçado o pelejar táo desesperadamente, que mataram dos castelhanos vinte e sete, morrendo dos nossos os treze e escapando os doze muito feridos. Foi muito honrado, e digno de memória pela desigualdade, que havia no número da gente castelhana ao dos nossos portugueses, pelejando mais a desesperação de sua perda, que algum bom discurso que os movesse a facção tão temerária ${ }^{27}$.

Não há nenhuma referência à condição social dos 25 portugueses que realizaram essa surpreendente empreitada. De fato, o que importa é a demonstraçáo do esforço dos lusos no enfrentamento dos castelhanos. Nenhum nobre, fidalgo ou mesmo homem de guerra nesse confronto: só há moradores e o alcaide da aldeia. Eles defendiam seus bens, seus remédios, contra seus inimigos de sempre, que agora lhes roubavam armados.

O tema é recorrente nas relaçóes portuguesas. Pelo mais comum, o anonimato cumpre esse papel, estimulando a identificação dos combatentes com todos os portugueses. Há relaçóes em que nenhum dos que resistem ao ataque inimigo é identificado por seu nome ou condiçáo social, outras que contam a resistência da população de uma vila ou aldeia, em que os combatentes são identificados por suas funçôes locais (padeiro, camponês, religioso etc.), como a relação da defesa de Santo Aleixo ${ }^{28}$.

Ocorrências como essas são indícios de que estes textos não eram voltados a um público seleto. Ao contrário, eram minuciosamente preparados para um público abrangente e deviam ser adequados a pessoas com diferentes níveis de alfabetização e leitura ${ }^{29}$. Afinal, aos envolvidos com a publicação dos textos importava tratar da coesão dos portugueses, de todos, independentemente de sua condiçáo social.

\footnotetext{
${ }^{27}$ Relação verdadeira da entrada que Governador das armas Mathias de Albuquerqe fez em Castella neste mes de Abril ano prezente de 1644 \& Sucesso de Montijo. Lisboa: Paulo Craesbeck, 1644. Sem paginação.

${ }_{28}^{28}$ AZEVEDO, Luís Marinho de. Relaçam de duas Vitorias que os moradores da aldeia de S. Aleixo, \& das villas de Mourão, \& Monsaras alcançarão dos castelhanos. Lisboa: Jorge Rodrigues, 1641.

${ }^{29}$ MARQUILHAS, Rita. A faculdade das letras. Leitura e escrita em Portugal no séc. XVII. Lisboa: Imprensa Nacional - Casa da Moeda, 2000.
} 
No que respeita à batalha que mais importa aqui, Montijo, a abordagem dos temas religiosos, tanto no que toca a uma possível intervenção divina direta, quanto ao respeito pelas igrejas em terras adversárias, é sempre um dos pontos mais importantes relatados. Ao invadirem Castela, os portugueses tinham por objetivo inicial tomar a vila de Albuquerque, conforme já foi dito. Uma vez constatada a inviabilidade da empresa, as tropas portuguesas se voltaram a arrasar diversos povoados nas proximidades, sendo o último deles Montijo. Antes disso, ao passarem por Vilar del Rey, as tropas portuguesas teriam arrasado uma igreja que servira de refúgio para os castelhanos ${ }^{30}$.

A relação que analisamos faz ressalvas que poderiam suavizar a notícia do incêndio do templo. No lugar de Membrilho, ainda no mesmo texto, os lusitanos teriam preservado o edifício religioso:

dentro de quatro horas foi assaltada, entrada, saqueada, e queimada, sem lhe ficar uma só casa, e somente escaparam os que se recolheram a uma Igreja, que estava bem fortificada, que da mesma maneira lhes valera, ainda que o não estivera, porque a veneração dos lugares sagrados aplaca logo a fúria dos nossos ${ }^{31}$.

Apenas a casa de Deus pareceu tocar os corações desses portugueses. Porém, o mais curioso não é a veneraçáo lusitana pela igreja ter salvado alguns poucos castelhanos, mas o efeito discursivo dessa passagem; afinal, depois de ter arrasado um templo em outra vila, os portugueses pouparam os inimigos recolhidos naquela de Membrilho. Na descrição do ataque à Villa Roca de Almançanete, o chefe das armas portuguesas, Mathias de Albuquerque, teria poupado o edifício religioso por não ocorrer ali os mesmos acontecimentos de Vilar Del Rey ${ }^{32}$. Com isso, ficavam entáo bastante "comprovados" os valores acertadamente cristáos destes soldados que, em vez de devastarem lugares santos, os preservam e cuidam, salvo quando serviam de fortalezas para seus inimigos, quando eles trocavam sua função religiosa por outra militar. Nesses casos, o argumento deixa claro que, antes de ser perversão atacar os que de dentro resistem, é erro de quem se vale desses lugares para se proteger das armas portuguesas.

A notícia do desfecho da batalha de Montijo correu rapidamente nos territórios da Monarquia. Embora as relações de Castela não tragam a data da publicação, alguns elementos nos permitem assegurar que o assunto tomou importância em Madri ainda antes do dia 31 de maio, conforme se pode verificar nos Avisos do cronista José de Pellicer de Tovar. As informaçóes ali recolhidas mostram um embate definitivamente ganho pelas forças da Monarquia sob o comando do barão de Molingen, com 3.500 inimigos mortos e a captura de onze peças de artilharia ${ }^{33}$. Nas suas anotaçóes seguintes, de 14 de junho, Pellicer de Tovar precisa suas informaçóes da batalha, após avisar que lhe viera uma relação do conflito ${ }^{34}$.

\footnotetext{
30 "Mathias de Albuquerque (...) saindo de Campo Mayor pessoalmente com seis mil infantes, e mil e cem cavalos e seis peças de artilharia, marchou contra Villar Del Rey, que tinha quatrocentos vizinhos, e a rendeu e arrazou derrubando-lhe a Igreja porque servia ao inimigo de fortificação". Relaçam Verdadeira, op. cit. p. 12-13.

${ }^{31}$ Ibidem, p. 10.

${ }^{32} \mathrm{O}$ general “(...) mandou queimar a Vila, e conservar a Igreja, sem que se tocasse a cousa alguma dela, porque não concorria nesta a mesma razão, que na de Vilar del Rey”. Ibidem, p. 13.

33 "Haviendo precedido algunas hostilidades entre los nuestros i los portugueses, i quemado el portugués un lugar llamado Zarça i nosotros el de Villarmayor, quiso el portugués poner sitio sobre Albuquerque. Y ayer por la mañana, vino aviso como, haviendo sabido este desígnio el de Torrecuso, trato de prevenir el daño; i contandole el passo, vino com el a las manos. Conseguió uma victoria no menos famosa que la de Lérida. Matole 3500 hombres, prendio 600 cavallos i once pieças de artilleria. Murió su General de la artilleria, i huyo Mathias de Albuquerque, su capitan general, yendo em su alcance el señor Baron de Molingen, nuestro Maestre de Campor Genral". TOVAR, José de Pellicer de. Avisos. Paris: Editions Hispaniques, 2002. v. I, p. 515.

${ }^{34}$ Cf. Ibidem, p. 519.
} 
Se as relaçóes, cartas e outros informativos de Castela saíram rapidamente da prensa, o material português demorou mais um tanto. Além disso, não se encontram relaçóes curtas, de quatro ou de oito páginas, apenas uma relativamente grande, de 36 páginas e preço não indicado, a Relaçam dos gloriosos svcessos, já citada. Esse texto foi enviado à publicaçáo em 11 de junho e saiu da prensa depois de 14 do mesmo mês; tempo incomum na publicação das relaçóes de guerra e um tanto suspeito, tendo em vista que se tratou do primeiro grande enfrentamento da guerra e da presteza das publicaçóes do inimigo.

A Relaçam mais parece uma crônica que um relato de combate. Ela abre seu conteúdo usando um vocabulário incomum nestas publicaçôes, mais afeto às profissóes letradas que aos leitores ávidos de informaçôes ligeiras: fala-se de "direito das gentes", das conquistas do ultramar, dos antigos reis de Portugal, da defesa da liberdade da pátria etc. Ainda trata de outros enfrentamentos com os castelhanos na Beira e em outras partes do território, ocorridas em abril e maio. A Relaçam termina com uma passagem que justifica o atraso na publicaçáo pela certeza na veracidade dos acontecimentos narrados:

Ainda que a relação da batalha de Montijo era desejada de muitos, pareceu que se devia deter alguns dias para que neles se pudesse apurar a verdade de todas as circunstâncias que dela aqui se referem, porque como nestas matérias as primeiras novas sempre são confusas e várias, não era bem que relação de coisa tão grande se estampasse menos comprovada do que convinha. Para o que aqui se escreve se juntaram as mais apuradas notícias que se puderam alcançar por avisos de pessoas que se acharam presentes, e tinham obrigaçáo de escrever a verdade, e o fizeram depois de a averiguar bem ${ }^{35}$.

De certa forma, o texto foi composto e publicado para contraditar os rumores que o inimigo difundia dentro e fora de Portugal para enfraquecer os ânimos, manter a desconfiança entre os portugueses e debilitar as alianças que o reino recém-liberto vinha fazendo com a Catalunha, a França, os Países Baixos, a Inglaterra e a Suécia ${ }^{36}$. O problema não era pequeno e envolvia um esforço incomum do novo governo em manter a confiança, já adquirida, na capacidade militar portuguesa entre os inimigos da Monarquia Católica.

De fato, Castela não descansou: certamente depois do dia 2 de julho de 1644, saiu publicada em Sevilha uma Relacion en Octavas Heroicas, composta por Antonio Pardo de Gayoso, capitáo de armas, que teria participado do combate ${ }^{37}$. O editor era Juan Gomez de Blas, cujo importante papel na imprensa sevilhana já foi estudado recentemente ${ }^{38}$.

Neste movediço terreno da viabilização da vitória em solo estrangeiro, para o novo governo português um sucesso na primeira grande batalha contra o castelhano viria a calhar, ainda que ele fosse proclamado também pelo inimigo. De fato, tão logo o governo de Portugal assentou sua própria versão da batalha, foram publicadas duas relaçóes em latim, evidentemente destinadas a um público extrapeninsular. Os textos são relatos sumários, elaborados a partir daquilo que ficou dito na Relaçam dos gloriosos svcessos. Uma delas saiu sem indicação de autor e sem cópia das licenças. A outra foi escrita por Francisco de Santo Agostinho de Macedo e saiu publicada depois de 2 de setembro de $1644^{39}$. Portugal disputava sua vitória sobre os castelhanos na diplomacia europeia, não mais em Lisboa, ou nos campos de Montijo.

\footnotetext{
${ }^{35}$ Relaçam dos gloriosos svcessos, op. cit. p. 34.

${ }^{36}$ Ibidem, p. 23.

${ }^{37}$ GAYOSO, Antonio Pardo de. Relacion en Octavas Heroicas, En que contiene todo lo real y verdadero del sucesso de la batalla del Montijo, auendose primero inuestigado las noticias mas indiuiduales: juntamente con aquellas de que fue testigo de vista, como quien se hallô en la batalla. Sevilla: Iuan Gomez de Blas, 1644.

${ }^{38}$ Cf. CALA, Carmen Espejo. El impressor sevillano Juan Gomez de Blas y los origenes de la prensa periódica. Zer, n. 25, p. 243-267, 2008.

${ }^{39}$ Cf. MACEDO, Francisco de Santo Agostinho de. Montigiensis de Castellano Hoste Victoria, auspiciis invictissimi Regis Joannis IV Portugaliae XVIII. Lisboa: Antonio Alvarez, 1644 (publicada depois de 2 de setembro de 1644).
} 
O governo da Monarquia Católica também não deixou de lado as possibilidades que se abriam em sua diplomacia com uma vitória no primeiro grande combate com as forças rebeldes do Bragança. Em junho de 1644, a Gazzetta di Genova publicou uma notícia da vitória das forças comandadas pelo marquês de Torrecusa sobre as de Mathias de Albuquerque. A iniciativa compunha o quadro de afirmação do vigor castelhano já divulgado nas relaçôes de Madri, de Salamanca, de Sevilha e talvez ainda por outras.

É bastante curioso constatar que a imprensa periódica portuguesa, inaugurada na Restauração, simplesmente ignora o conflito de Montijo. A Gazeta sequer trata da matéria em seus números de maio e junho, nem nos de julho e agosto. Certamente, essa aparente indiferença se deveu aos conflitos que levaram à supressão das notícias do reino naquele periódico, o que vem a somar evidências, ainda que seja pela ausência de registro, de que a vitória portuguesa foi fabricada entre o campo da batalha e Lisboa.

Neste novo campo de embate, o das publicações, respondeu Portugal às iniciativas castelhanas pela pena do capitão Luís Marinho de Azevedo, um já celebrado autor de relaçôes de guerra. Sua resposta é a Apologia Militar em Defensa de La Victoria de Montijo contra las relaciones de Castilla, y gazeta de Genoba, que la calumniaron mordaces, y la usurpan maliciosas, publicada em 15 de outubro de 1644, mas escrita antes de 15 de setembro ${ }^{40}$. Trata-se, de fato, de uma obra de controvérsia em que Luís Marinho rebate as relaçóes de Castela sobre o feito de Montijo. Ao todo, ela conta 24 páginas.

Sua carga descritiva é bastante reduzida, afinal, trata-se de uma apologia, de um texto destinado a defender a vitória portuguesa em controvérsia com os textos de Castela e com a Gazzetta di Genova. Não se tratava de um informativo. Outra diferença básica: a língua. $\mathrm{O}$ autor não perde tempo em sua narrativa e explica, já no começo, a razão pela qual adotou o castelhano em seu texto: " $y$ para que lo entiendan mejor se lo escriviremos en su lengua materna" ${ }^{\text {"11 }}$, como se o problema fosse a compreensão da língua portuguesa por parte dos castelhanos.

Esse impresso carrega ainda certa carga de erudição não registrada nos demais impressos sobre o mesmo feito. $\mathrm{Na}$ verdade, esse texto não está somente dirigido a concretizar uma realização do povo português, está ainda orientado a debater diretamente com os defensores das outras versôes. Assim, fica seguramente apontada uma disputa política voltada a solucionar um problema que comumente se pensa ser apenas bélico. O próprio Azevedo deixa isso expresso em palavras:

pues no puede ser mayor para nuestra reputacion, que vender Castilla por suya la victoria de Montijo, theatro fatal de la nobleça de Estremadura; hablando con estylo repugnante a toda urbanidad, verdad, y noticias, affectando jactancias, y divulgando uanidades. Es la defensa cosa natural, y saben los Portuguezes disponerla con espada, y con la pluma, sustentando con las armas su justicia, y con las letras el derecho della, que eran las leyes de que se valia Pompeyo en Plutarcho ${ }^{42}$.

Azevedo, de fato, já havia mostrado um tipo de alinhamento bastante expressivo no conjunto dos escritos da Restauração. Suas relaçóes de guerra revelam que se trata de autor que sempre apresenta os feitos portugueses resultantes da ação da gente comum das cidades, em defesa de seus bens e de sua liberdade, ou do empenho de seus soldados. Não se trata de autor engajado na celebração de um chefe militar ou outro que, por suas virtudes especiais, consegue uma vitória miraculosa. Ele exalta a ação dos chefes, mas também a dos homens que combatem! Para Luís Marinho de Azevedo, o reino se libertou de Castela; não foi libertado por d. João de Bragança. Mais que tanto, ele deixa claramente exposta a participação da população dentro das fronteiras do reino, quando narra que o novo rei saiu a pé do

\footnotetext{
${ }^{40}$ Cf. Lisboa: Lourenço de Anvers, 1644 (publicada em 15 de outubro de 1644).

${ }^{41}$ AZEVEDO, Luís Marinho de. Apologia Militar, op. cit. p. 2.

${ }^{42}$ Ibidem.
} 
palácio e se dirigiu à Sé de Lisboa, acompanhado de toda a corte, aos olhos das gentes da cidade ${ }^{43}$. Ao final, Azevedo completa seu elogio aos "muros da pátria":

Despues de aver respondido a las calumnias de nuestros enemigos nos quedava largo campo, para encarecer con los hyperboles mas levantados las acciones particulares del Governador de nuestras armas, y de las de mas personas de puestos superiores, Capitanes, y officiales que las mandaron, y exercitaron en batalla tan bien peleada: però temiendo la pluma el caudal que demanda tanto empeño retrocede al querer hacerlo por evitar las queixas de los que en la estimacion de sus meritos afiançan la singularidad de sus hazañas, que está mas obligado a referir el que escriviere historia. Mudando de estylo hablo con vosotros soldados de menos nombre, que pues en tan gallarda accion mostrastes ser los muros de vuestra patria; como Agesilao publicava por excellencia de los lacedemonios. Si falta siempre escriptor de vuestros hechos, el ignorar vuestros nombres me priva de que no lo sea, con elogios devidos a la fama que os immortaliza; para que la gloria que se compro con vuestra sangre, no se adjudique a algunos que en ella tubieron menor parte $e^{44}$.

O próprio autor explica o abandono da gravidade de seu texto, mudando de estilo, por força talvez de um desejo de impactar os muitos nobres e fidalgos portugueses que, por fidelidade ou insegurança quanto ao projeto político brigantino, permaneceram em Madri obedientes a Felipe IV. Percebe-se então que a intervenção política feita por meio destes impressos, e ainda pelos impressores, era também voltada ao público lusitano, configurando assim importante arma política no estabelecimento do novo governo de Portugal.

Mas o problema principal naquela altura dos acontecimentos era o enfrentamento dos escritos de Castela. Em especial, o contraste apresentado por Azevedo às Octavas Heroicas de Antonio Pardo de Gayoso.

$\mathrm{O}$ autor das Octavas dedica alguns versos em agradecimento a Deus, ao marquês de Torrecusa e ao barão de Molingen, a quem o marquês atribuiu a missão de expulsar as tropas de Mathias de Albuquerque. Dirigindo-se a Deus, ele lembra a profanaçáo da igreja feita pelos portugueses e reconhece a derrota lusitana como justo castigo por a terem queimado:

Vos solo sois el justo y todo santo,

Castigando en sacrilegia indecencia,

Lo que ofreceis en tan seuero exemplo,

A quien profana vuestro sacro Templo ${ }^{45}$.

Tal e qual a Relaçam portuguesa, a vitória é atribuída à vontade divina, como se o Deus dos castelhanos não fosse o mesmo! Azevedo avança sobre as Octavas usando recursos literários bastante eficientes, especialmente a ironia, quando aborda o espinhoso problema do número de combatentes de cada lado. O sargento-mor de Castela afirmou que as tropas seriam da ordem de 1.200 infantes castelhanos amparados por 1.300 cavalos e quatro peças de artilharia, já as de Portugal somariam 6 mil infantes, 1.500 cavalos e seis peças de artilharia, além dos carros de bagagens e butim das vilas devastadas ${ }^{46}$. Mas os esquadróes de infantaria formavam em quadrados compactos para as batalhas daquele tempo, e cabia exatamente ao sargento-mor a ordenação dos homens nessa forma específica. Assim, ele deveria extrair a raiz quadrada do total para definir o número de soldados em cada linha do esquadrão. $\mathrm{O}$ capitão por-

\footnotetext{
${ }^{43}$ Ibidem, p. 22-23.

${ }^{44}$ Ibidem, p. 23.

${ }^{45}$ GAYOSO, Antonio Pardo de. Octavas Heroicas, op. cit. p. 12.

${ }^{46}$ Ibidem, p. 3, 4, 7.
} 
tuguês ridiculariza o sargento lançando mão de seus conhecimentos de aritmética, fazendo trocadilhos com o nome de seu oponente e com elementos da mitologia grega:

Dice tambien el mayor de los sargentos, que sus infantes eran tres mil, y mil, y trecientos los cavallos, y que los nuestros eran mil, y quinheñientos, y seis mil infantes, y si no sabe mejor Arismetica para formar esquadrones de hombres, que numero de cavallos sabrá para sacar la raiz quadrada: pero como deviò de contarlos con nubes pardas en los ojos, o con antojo de larga vista no acertò bien los guarismos: si no es que el dicho poeta Pardo bevio en la fuente del cavallo Pegaso tales spiritus cabalinos, que pone, y quita cavallos con la facilidad, que el lo sabe hacer ${ }^{47}$.

De fato, a Apologia não era um informativo ligeiro como os muitos que Azevedo escreveu nos primeiros anos desta guerra. Aqui, ele não só se refere à erudição militar que obriga certo conhecimento aritmético, mas também ao rio Hipocrene que, segundo a mitologia, nasceu de um coice do cavalo Pégaso e cujas águas tornariam poeta qualquer um que as bebesse. Azevedo sugere que os números de Gayoso são mais liberdade poética que fato.

Mas, como o problema não se restringe à aritmética, Gayoso avança uma descrição do confronto. O final da batalha apresentado pelo poeta de Sevilha faz depender do descuido de um único soldado de Castela todo o destino da artilharia portuguesa capturada e, com isso, o elemento básico utilizado pelos escritores de Portugal a seu favor:

\section{Ganose de vez su Artilleria, dezandola por nuestra retroguarda, sin que aduirtiesse nuestra Infanteria, retirarla, ò ponerla alguna guarda: Vn traydor de los nuestros, que serra de lealtad sospechosa, si bastarda, por lleuarse las mulas que la tira, queda oluidada, y nadie la retira ${ }^{48}$.}

Ao contrário da Relacion Verdadera castelhana, Gayoso culpa um soldado, não nomeado, por seu "descuido" em deixar a artilharia levando os animais. Contudo, uma curiosa contradição se apresenta: se os canhôes encontravam-se agora sem as mulas que os puxassem, como foram deslocados pelos portugueses, que, aliás, já tinham perdido seus haveres? Nenhum relato português ou castelhano explica como eles conseguiram levá-los, uma vez que já não contavam com auxílio de seu gado. Porém, para as Octavas, a infâmia portuguesa permanece não só pela derrota material, mas também pela fuga desordenada que os fez perder muitos ganhos, salvo os canhóes.

Azevedo desperdiça essa contradição em favor de um desfecho que valoriza o comando português da batalha. As decisóes do governador das armas se dão amparadas em um profundo conhecimento das Artes Militares, que Azevedo dá mostras de também conhecer. Segundo o capitão, após uma breve reunião dos comandantes ficou decidido que

avian de hacer aprieto semejante: siguieron el parecer del tragico Seneca, que en los males ciertos se avia de tomar el camino mas arriscado. Este lo fue sacar las espadas, y animando a los soldados, exortalos a hacer lo mismo, por consistir en la resolucion de defenderse con ella en la mano, el morir honrados, haciendo las ultimas pruebas del

\footnotetext{
${ }^{47}$ AZEVEDO, Luís Marinho de. Apologia Militar, op. cit. p. 25.

${ }^{48}$ GAYOSO, Antonio Pardo de. Octavas Heroicas, op. cit. p. 10.
} 
balor Portuguez, ya que no les quedava mas esperança de remedio, que la de su propria virtudy fureças: considerado el sitio en que se hallavan para pelear como el Tacito encarecia del balor de los soldados Romanos en otro aprieto ${ }^{49}$.

Mesmo numa passagem catártica como essa, a erudição que estrutura o argumento diferencia a Apologia das relaçôes de guerra: aqui, a fúria é douta. $\mathrm{O}$ autor concilia a ação dos soldados com a sabedoria de Sêneca e de Tácito e em escolhas acertadas que soam frias e lógicas. A essa reação das tropas portuguesas seguiu uma reestruturação das formaçôes e, consequentemente, a vitória final. A escolha desses argumentos com certeza ocorreu em função do caráter de réplica assumido pelo impresso. Apesar do debate promovido por Azevedo e pelas grandes divergências dos fatos narrados, o que nos é mostrado pelo conjunto de textos é uma história resolvida, embora com duas versóes bastante diferentes. É necessário sublinhar que todos esses textos são conformadores de duas histórias consistentes sobre um mesmo evento.

Entre os autores portugueses, também outros se dedicaram à publicação de crônicas da guerra com Castela naqueles primeiros anos do conflito. João Salgado de Araújo, por exemplo, adiou a publicação de sua crônica dos primeiros anos da guerra em função do andamento dos combates, de questôes outras, mas também da importância da controvérsia sobre o resultado da batalha de Montijo. O livro Sucessos Militares das Armas Portuguesas obteve as licenças de publicação ainda em abril de 1644 (22 de abril, precisamente); mas a obra só veio à luz em 17 de dezembro após uma segunda rodada de aprovaçóes. O problema que tratamos aparece logo no início da narrativa:

Ainda que a batalha de Montijo anda pontualmente escrita numa relação de grande crédito, me pareceu iria falto este papel sem ela, pela terribilidade e esforço valoroso, que nossa gente nela mostrou no cabo de algum tempo, que pisavam terras do inimigo, sem haver alguém que lhes ousasse sair, carregada de muitos e ricos despojos que traziam. O qual poderá ser causa dos castelhanos desbaratar e vencer nosso exército, mas eles não prestaram para isso, nem puderam aproveitar-se da ação, remeteram o crédito de suas armas ao estrondo dos seus gazeteiros, com só isso se consolaram das muitas mortes que padeceram ${ }^{50}$.

A "relação de grande crédito" certamente é o texto já citado, a Relaçam dos gloriosos svcessos. Mas foi o estrondo dos gazeteiros de Castela que lhes salvou o crédito nas armas, e não os feitos de armas que sustentaram seus animados impressores. No segundo semestre de 1644, ainda se disputava a vitória de maio em Montijo.

Quando o assunto ainda estava quente, nos meses que seguiram a maio de 1644, a batalha virou matéria para o periodismo emergente na Europa de então e para a campanha publicística dos países que se opunham à Monarquia Católica. A lógica da viabilização da vitória em Montijo por meio das relaçóes informativas ultrapassou as fronteiras de Portugal, chegando à França e à Catalunha, como já foi dito. Expressivo é seu desembarque na Inglaterra ainda em 1644, com a publicação de um folheto sobre a polêmica. O texto inicia com uma passagem que declara exatamente o ponto que mais interessa no presente trabalho:

\footnotetext{
${ }^{49}$ AZEVEDO, Luís Marinho de. Apologia Militar, op. cit. p. 11.

${ }^{50}$ ARAÚJO, João Salgado de. Sucessos Militares das Armas Portuguesas em suas fronteiras depois da Real Aclamação contra Castela. Lisboa: Paulo Craesbeeck, 1644.
} 
It is so fatall to the spaniard to be beaten by the portuguesses, that not content to overcome by force of armes, they invent new wayes to augment their own overthrows: and this appeareth evident by their late publishing a mighty victory which they (forsooth) had newly obtained over the portugesses in the skirts of Spaine; whereas within very few days after this lowd lyes publication, there arrived here most certain newes of the selfsame defeat given in the same time and place, unto the spaniards, by the portuguesses, which they had vapoured to have bin given by then unto the portuguesses, so that by this we see the Spaniards are not content to be quelled by the sword of the portugall, but they must needs also be confounded by their own lies, to make their shame the greater' ${ }^{\text {I }}$

Este folheto certamente foi publicado depois de junho de 1644. Afinal ele faz referência à elevação de Mathias de Albuquerque a conde de Alegrete, o que ocorreu no mês seguinte à batalha ${ }^{52}$. A apressada atribuição desse título de nobreza soa forte como mais um elemento de viabilização da vitória portuguesa do que uma mercê sobre serviços prestados à monarquia portuguesa. Não deveria ser comum um fidalgo militar de vida bastante conturbada, tendo estado preso pelo antigo governo castelhano pela perda de Pernambuco e, depois de julho de 1641, novamente preso por suspeita de traição, receber um título de nobreza com tanta rapidez após uma vitória militar controvertida. É importante lembrar que a atribuiçáo de títulos de nobreza era prêmio maior na sociedade portuguesa daquele tempo.

Algumas décadas depois, as histórias da retomada da independência portuguesa acessaram as informações então disponíveis sobre a batalha. Enfim, a guerra fora vencida pelos lusitanos e aquela que teria sido a primeira vitória se apresentava como um elemento sólido para propagar a constância portuguesa em seus esforços de reconquista da liberdade. O conde da Ericeira, em sua clássica História de Portugal Restaurado, publicada ainda no século XVII, reproduz o conteúdo básico da Relaçam, agregando discursos patrióticos e regalistas atribuídos a Mathias de Albuquerque e ao barão de Molingen, coagulando uma versáo já bastante conhecida e debatida dos acontecimentos.

Mas o assunto náo era apenas lusitano ou ibérico e o feito português, que demorou quase trinta anos para se efetivar, interessava sobremaneira aos inimigos da Monarquia Católica. De fato, na série de obras publicadas na Europa, sobressaem as versóes que estamos analisando. Por exemplo, na obra do veneziano Giovanni Battista Birago sobre a Restauração de Portugal, publicada em Lyon, ainda em 1646, vê-se claramente que o texto da Relaçam portuguesa foi praticamente traduzido ao italiano ${ }^{53}$. A obra de Birago apresenta-se como um escrito de uma guerra que apenas começava quando foi editada e não havia nada que sugerisse a definição de seu resultado.

Mais de vinte anos depois de terminado o conflito, outra obra de autor veneziano sai da prensa contando a história da Restauração; trata-se do livro de Alessandro Brandano, História delle Guerre di Portogallo, em que as informaçóes sobre Montijo repetem os ditos de Birago e da Relaçam comentados mais acima ${ }^{54}$. É importante registrar que, enquanto o primeiro veneziano foi patrocinado pelo rei da França, o segundo foi financiado por d. Pedro II de Portugal, filho de d. Joáo.

A Monarquia Católica, mesmo obrigada a aceitar a independência portuguesa, perdida a guerra, não deixou de financiar quem contasse sua história. O rei Carlos II patrocinou a obra latina de Gaetano Passarello sobre a Restauração, publicada em $1684^{55}$, que conta versão castelhana da batalha de Montijo, grosso modo, a mesma que comentamos anteriormente.

\footnotetext{
${ }^{51}$ The Reall Victorie of Portugall. Londres: 1644. p. 1.

52 "[the King] creating the general of this victorious armie Mathias de Albuquerque Count of Alegrete, gave him a revenue of 4000 ducats a yeare". Ibidem, p. 5.

53 BIRAGO, Giovanni Battista. Historia della Disunione Del Regno di Portogallo dalla corona di Castiglia. Amsterdam: Nicolau Van Ravesteyn, 1647. p. 713-722.

${ }^{54}$ BRANDANO, Alessandro. Historia delle Guerre di Portogallo, Veneza: Paolo Baglioni, 1689. p. 306-310.

${ }_{55}$ PASSARELLO, Gaetano. Bellum Lusitanum Ejusque Regni Separatio a Regno Castellenensi. Lyon: Rigaud, 1684. p. 201-206.
} 
Ao longo dos séculos seguintes, Portugal contentou-se com reediçóes da grande obra do conde da Ericeira, cujo conteúdo relativo a Montijo, como vimos, depende do texto publicado em junho de 1644 . $\mathrm{O}$ tema chega aos nossos dias praticamente inalterado. De fato, boa parte das obras mais recentes repete o enquadramento de Ericeira, sem maiores consideraçóes críticas. É o caso do livro do general Gabriel do Espírito Santo ${ }^{56}$, publicado recentemente. Já Fernando Dores Costa, em seu estudo de há alguns anos, identifica uma controvérsia sobre a vitória de Montijo e adota uma posiçáo que parece aceitar que houve duas vitórias na batalha: uma primeira, castelhana, ganha no início do combate, e a segunda, portuguesa, quando os lusitanos recuperaram seu armamento pesado. De fato, não estáo entre suas preocupaçóes o significado da propaganda na diplomacia e na guerra, e o que isso revela acerca do papel da opinião no desfecho dos grandes conflitos militares do século XVII e nesse conflito ibérico ${ }^{57}$. Essa guerra, ou qualquer outra, não era apenas um feito de homens armados; envolvia também aqueles que os mantinham, que participavam dos acontecimentos à distância, e cuja opinião sobre os feitos bélicos era fundamental tanto para a formação do exército quanto para a própria sustentação do governo. Certamente não será opção radical escrever uma nova história militar sem considerar a disputa pela opinião como elemento central dos acontecimentos.

Neste esforço mais recente de analisar a guerra e fixar uma versão dos acontecimentos ligados à retomada da independência portuguesa, Castela também não abriu mão da vitória. Perdera a guerra após uma série longa de batalhas importantes em que não era possível sustentar que vencera, mas Montijo continuou a ser sua. Com a consolidação da independência portuguesa foi-se uma parte importantíssima de suas conquistas e não caberia disputar por longo tempo a história de sua derrota, mas não concedeu a vitória na batalha aos portugueses ${ }^{58}$. Confirma isso Serafín Estebañez Calderon quando escreveu, no século XIX, sobre a conquista e perda de Portugal. Em seu tratado, o autor assegura que Montijo foi uma batalha vencida por Castela; porém, mal vencida, pois permitiu aos portugueses a retomada de sua artilharia e, com isso, a possibilidade da defesa errônea de sua vitória. Em alguns momentos, d. Serafín parece escrever no próprio tempo em que os acontecimentos ocorreram ${ }^{59}$; sua análise da batalha baseia-se exclusivamente no material castelhano: cartas oficiais, relações impressas etc. Sua conclusão sobre a batalha de Montijo parece emergir diretamente das relaçôes da época, num esforço de reviver a batalha e seu desfecho, séculos após os acontecimentos:

Albuquerque, quebrantado en sus ánimos y en sus fuerzas, hubo de retirarse a Portugal; mas, satisfecho de haber cobrado su artilleria, llevo su jactáncia hasta atribuirse la victoria. Braganza, porque le importava tambien disimular este reves, adopto la própia mentira, y mando celebrar el sucesso con fiestas publicas en todos sus dominios, bien que harto contradijeron aquellas muestras el luto y pesar de que se cubrio Lisboa, con tantas famílias como hubo que llorasen alguno de los suyos, muertos o prisioneros en la batalla ${ }^{60}$.

Embora a importância desta batalha tenha praticamente desaparecido ao longo dos séculos, até hoje as interpretaçóes do acontecido permanecem deste mesmo modo: duas vitórias num mesmo confronto

\footnotetext{
${ }^{56}$ ESPÍRITO SANTO, Gabriel do. A grande Estratégia de Portugal na Restauração, op. cit.

${ }^{57}$ COSTA, Fernando Dores. A Guerra da Restauração. Lisboa: Horizonte, 2004. p. 56.

${ }^{58} \mathrm{O}$ exame mais detalhado da historiografia espanhola sobre suas antigas guerras não consta entre nossas intençóes e nem corresponderia ao escopo deste trabalho. Tal limitaçáo decorre de opçóes primeiras do trabalho, concentrando nossas atençóes nos estudos portugueses.

59 "Ya eran transcurridos cuatro años de guerra, y corria el de 1644, cuando la indignación de los castellanos, al verse burlados por los portugueses, pueblo pequeño y encerrado en un confin de la Peninsula, encendió de nuevo y con más furor las hostilidades”, CALDERON, Serafín Estebañez. De la Conquista y Pérdida de Portugal. Madri: Perez Dubrull, 1885. v. I, p. 107.

${ }^{60}$ Ibidem, p. 124. Aqui, o historiador castelhano praticamente repete o dito de Gaetano Passarello, cf. PASSARELLO, Gaetano. Bellum Lusitanum Ejusque Regni Separatio a Regno Castellenensi, op. cit. p. 206.
} 
militar. O assunto não fica restrito aos debates de historiadores militares de Portugal e da Espanha modernos: a própria população da cidade de Montijo demonstrou seu ponto de vista numa representação pública envolvendo mais de 250 moradores da cidade há uns poucos anos, conforme já dissemos no início deste trabalho.

De fato, nesta altura dos acontecimentos, no século XXI, pouco importa a materialidade do desfecho dessa batalha; salvo para os moradores de Montijo e para os historiadores militares de Portugal. Já se foi o tempo em que as animosidades ibéricas governavam temas da cultura política; elas estáo restritas ao anedotário de vizinhos e parecem não ter mais qualquer eficácia. Vive-se hoje a estratégia da submersão de tensôes ancestrais num quadro de fortalecimento da unificação política continental da Europa. Assim, o debate sobre a conquista da vitória numa batalha antiga mergulha na obsolescência. É tarefa difícil — talvez impossível — averiguar qual versão dos fatos obteve maior credibilidade. Seja como for, não será exagerado dizer que, quem quer que tenha sido seu vencedor material no distante tempo em que ocorreu, a batalha de Montijo foi "ganha no grito". 